\title{
THE
}

\section{Effects of Developmental Deltamethrin Exposure on White Adipose Tissue Gene Expression}

\author{
Laura E. Armstrong \\ University of Rhode Island \\ Maureen V. Driscoll \\ University of Rhode Island \\ Vijay R. More \\ University of Rhode Island \\ Ajay C. Donepudi \\ University of Rhode Island \\ Jialin Xu \\ University of Rhode Island
}

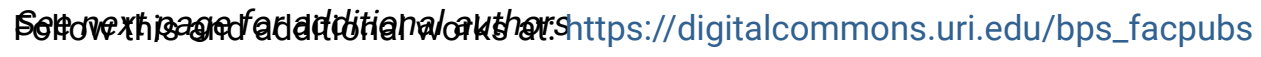

This is a pre-publication author manuscript of the final, published article.

Terms of Use

All rights reserved under copyright.

\section{Citation/Publisher Attribution}

Armstrong, L. E., Driscoll, M. V., More, V. R., Donepudi, A. C., Xu, J. , Baker, A. , Aleksunes, L. M., Richardson, J. R. and Slitt, A. L. (2013), Effects of Developmental Deltamethrin Exposure on White Adipose Tissue Gene Expression. J Biochem Mol Toxicol, 27: 165-171. doi: 10.1002/jbt.21477

Available at: https://doi.org/10.1002/jbt.21477

This Article is brought to you for free and open access by the Biomedical and Pharmaceutical Sciences at DigitalCommons@URI. It has been accepted for inclusion in Biomedical and Pharmaceutical Sciences Faculty Publications by an authorized administrator of DigitalCommons@URI. For more information, please contact digitalcommons-group@uri.edu. 


\section{Authors}

Laura E. Armstrong, Maureen V. Driscoll, Vijay R. More, Ajay C. Donepudi, Jialin Xu, Angela Baker, Lauren M. Aleksunes, Jason R. Richardson, and Angela Slitt 


\title{
Effects of Developmental Deltamethrin Exposure on White Adipose Tissue Gene Expression
}

\author{
Laura E. Armstrong ${ }^{1}$, Maureen V. Driscoll ${ }^{1}$, Vijay R. More ${ }^{1}$, Ajay C. Donepudi ${ }^{1}$, Jialin Xu ${ }^{1}$, \\ Angela Baker $^{2}$, Lauren M. Aleksunes ${ }^{3}$, Jason R. Richardson ${ }^{2}$, and Angela L. Slitt ${ }^{1}$ \\ ${ }^{1}$ Department of Biomedical and Pharmaceutical Sciences, University of Rhode Island, Kingston, \\ RI 02881, USA \\ ${ }^{2}$ Department of Environmental and Occupational Medicine, University of Medicine and Dentistry \\ of New Jersey, Piscataway, NJ 08854, USA \\ ${ }^{3}$ Department of Pharmacology and Toxicology, Rutgers University, Piscataway, NJ 08854, USA
}

\begin{abstract}
Deltamethrin, a type II pyrethroid, is a widely used insecticide. The purpose of this study was to determine whether perinatal deltamethrin exposure altered the expression of adipogenic and lipogenic genes in white adipose tissue (WAT) in adult pups. C57BL/6 pregnant mice were administered 0,1 , or $3 \mathrm{mg} / \mathrm{kg}$ of deltamethrin orally every 3 days throughout gestation and lactation. Offspring were weaned on postnatal day 25, and WAT was collected from 5-month-old male mice. Perinatal deltamethrin exposure decreased the mRNA expression of adipogenesisrelated transcription factors Ppar $\gamma$, Cebp $a$, and lipogenic genes Srebp1c, Acc-1, Cd36, Lpl, Scd-1; along with Nrf2 and target genes Nqo1 and Gclc at the $1 \mathrm{mg} / \mathrm{kg}$ treatment. Cytokine expression of Fas/Tnf-R and Cd209e at the $1 \mathrm{mg} / \mathrm{kg}$ treatment was significantly decreased, and expression of Tnf, Cd11c, and Fas/Tnf-R was decreased at the $3 \mathrm{mg} / \mathrm{kg}$ treatment. Developmental deltamethrin exposure did not overtly affect body weight or adipose weight, but decreased mRNA expression of specific genes that may poten tially disrupt normal adipogenesis and lipid and glucose metabolism if the offspring are challenged by changes in diet or environment.
\end{abstract}

\section{Keywords}

Deltamethrin; White Adipose Tissue; Adipogenesis; Perinatal; Pyrethroid

\section{INTRODUCTION}

Pyrethroids are synthetic chemicals modeled after the naturally occurring pyrethrins, found in chrysanthemums [1]. Type I and type II pyrethroids are commonly used as potent and effective insecticides for agricultural and public health applications [2] and can easily enter

\footnotetext{
(c) 2013 Wiley Periodicals, Inc.

Correspondence to: A. L. Slitt. aslitt@etal.uri.edu.
}

This work was presented, in part, at the Annual Society of Toxicology meeting held March 12-15, 2012, in San Francisco, CA and at the Northeast Society of Toxicology meeting held October 19, 2012 at Salve Regina University, Newport, RI. 
the exoskeleton of insects. These axonic poisons cause paralysis and ultimately death of the organism by keeping sodium channels open in the neuronal membranes. Type II pyrethroids, such as deltamethrin, are defined by an $a$-cyano group that is known to produce a long lasting inhibition of voltage-activated sodium channels [1,2]. Pyrethroid pesticides are often thought of as "safer" alternatives to the more toxic organophosphates because of their low mammalian toxicity. This relatively low toxicity is attributed to a combination of efficient detoxification mechanisms in mammals [3] and lower sensitivity of ion channels [2]. However, metabolic detoxification mechanisms are not fully developed in very young mammals, potentially increasing susceptibility to pyrethroids in this population [4]. This is particularly crucial because pyrethroid use has increased tremendously since the cancellation or reduction in the use of many organophosphorus pesticides [5]. In recent years, significant levels of pyrethroid metabolites, including those of deltamethrin, have been found in the urine of pregnant women and children [6-9]. Furthermore, deltamethrin, which is widely used to control malaria vectors, has also been detected in the breast milk of South African women [10]. The latter data pose questions regarding the safety of deltamethrin, as developmental neurotoxicity and other adverse developmental effects are currently being studied in these susceptible populations [1].

Adipose tissue is a lipophilic tissue that is metabolically active and essential for the proper maintenance of systemic energy balance. Adipogenesis requires a highly regulated cascade of transcription factors, including C/EBP family and $\operatorname{Ppar} \gamma$, which regulate the differentiation of preadipocytes to adipocytes [11]. Most recently, this cascade of transcription factors has been proven to be regulated by Nrf2, a well-defined transcription factor of oxidative stress $[12,13]$. The three major functions of adipose tissue are lipid storage and mobilization, glucose homeostasis, and endocrine function, involving secretion of hormones, cytokines, and transcription factors [11,14]. Changes in the expression of transcription factors involved in adipocyte differentiation during development can lead to dysfunction in the metabolic and endocrine functions of white adipose tissue (WAT), as demonstrated by gene knockdown, knockout, and induction studies [11, 14]. When characterizing deltamethrin as a safe pesticide, The World Health Organization (WHO) observed lower body weight (BW) gain in adult rats that were orally administered the pesticide, decreased mean fetal weights with a perinatal high dose of $10 \mathrm{mg} / \mathrm{kg} \mathrm{BW}$, and a dose-related decrease in BW of postnatal mice [15]. Despite increased research on the developmental toxicology of pyrethroids, to our knowledge, no studies have addressed whether exposure to pyrethroids during developmental stages affects adipose tissue development and homeostasis. Therefore, the purpose of this study was to address the potential metabolic effects of perinatal deltamethrin exposure in WAT, to address previously described changes in BW during development.

\section{MATERIALS AND METHODS}

\section{Animals}

Eight-week-old female and male C57BL/6J mice purchased from Jackson Laboratory (Bar Harbor, ME) were used. Mice were maintained on a 12:12 light/dark cycle with food and water available ad libitum. All procedures were conducted in accordance with the $N I H$ 
Guide for Care and Use of Laboratory Animals and approved by the Institutional Animal Care and Use Committee at Robert Wood Johnson Medical School.

\section{Treatment}

10-week-old female C57BL/6J mice were individually housed and mated with C57BL/6J males. Upon identification of a vaginal plug, males were removed and single-housed female mice were administered 0 (control), 1 , or $3 \mathrm{mg} / \mathrm{kg} \mathrm{BW}$ deltamethrin (ChemSer-vice, West Chester, PA), dissolved in corn oil and mixed with peanut butter ( $100 \mathrm{mg}$; Skippy Creamy Peanut Butter) every 3 days throughout gestation and lactation as described previously [1618]. Mice were monitored to ensure total consumption of the treatment dose, which generally occurred within $10 \mathrm{~min}$. This administration method reduces handling stress associated with injections during pregnancy and most closely mimics human oral exposure conditions $[16,17]$.

The dose selected in this study is one-fourth of the developmental No observable adverse effect level (NOAEL) [19]. Unfortunately, the rapid metabolism of pyrethroids has made dose extrapolation difficult. There have been no comparative studies in rodent and humans to determine half-lives of the parent compound, but separate studies have presented the halflife of deltmethrin, in humans and rats, to appear to be in a similar range of several hours. It should be noted that recent pharmacokinetic modeling in rats predicted that humans would experience a higher brain concentration of deltamethrin compared to rodents, most likely because humans do not have plasma carboxylesterase activity [20].

The offspring were weaned at postnatal day 25 , and once weaned; offspring received no additional exposure to deltamethrin. The time point of 5 months was selected because tissues were being shared from a cohort, from a study being conducted by Dr. Richardson's group for the primary purpose of developmental deltamethrin effects on behavior. These cohorts had been assessed for neurobehavioral changes, and 5 months was determined to be an appropriate time of necropsy for Dr. Richardson's study. As 5 months represent adulthood and mature adipose tissue, WAT was evaluated for changes in expression of genes related to adipogenesis, lipid synthesis, glucose uptake, and inflammation.

Prior to sacrifice, blood glucose concentrations were obtained via tail vein nick and measured using a TRUEtrack ${ }^{\mathrm{TM}}$ glucometer. Animals were not fasted prior to sacrifice. Mice were sacrificed by $\mathrm{CO}_{2}$ inhalation followed by cardiac puncture for blood collection at 5 months of age. Blood was centrifuged at 14,000×g for $10 \mathrm{~min}$ to obtain serum. WAT from the abdomen was removed and snap frozen in liquid nitrogen. Samples were stored at $-80^{\circ} \mathrm{C}$ until shipment to University of Rhode Island on dry ice. Dosing of mice and sample collection was carried out by the laboratory of Dr. Jason Richardson at the University of Medicine and Dentistry of New Jersey, Piscataway, NJ.

\section{RNA Extraction}

Perinatal exposure to deltamethrin causes postnatal behavioral changes in adult male, but not female off-spring (Richardson et al., submitted). For this reason, adult male mice were selected for the current investigation. Total RNA was isolated from 50-100 mg frozen WAT 
from the male 5-month cohort via homogenization in Trizol ${ }^{\mathrm{TM}}$ lysis buffer (Life

Technologies, Grand Island, NY) followed by chloroform-isopropanol extraction. The RNA concentration was determined by measuring UV absorbance of the sample at $260 \mathrm{~nm}$ using NanoDrop $^{\text {TM }}$ (Wilmington, DE), and RNA integrity was confirmed by the presence of distinct $18 \mathrm{~S}$ and $28 \mathrm{~S}$ bands using formaldehyde-agarose gel electrophoresis. RNA samples were stored at $-80^{\circ} \mathrm{C}$ until utilized.

\section{Quantigene Plex 2.0 Assay}

Total RNA was applied to the Quantigene Plex (Affymetrix, Santa Clara, CA) and hybridized overnight at $54^{\circ} \mathrm{C}$ with specific mRNA capture beads and capture probes. The following day, the samples were hybridized with preamplifier followed by amplifier incubation and a biotinylated label probe for $1 \mathrm{~h}$ at $50^{\circ} \mathrm{C}$ followed by application of streptavidinconjugated phycoerythrin detection probe for $30 \mathrm{~min}$ at room temperature. The plex was analyzed on a Luminex Bio-Plex 200 array reader with Luminex 100 xMAP technology (Austin, TX). mRNA expression was normalized to the Rpl13a housekeeping gene, which was not significantly different between treatment groups. Only male gene expression in adipose tissue was determined in an attempt to reduce gender variability as a confounding factor.

\section{qPCR mRNA Quantification}

qPCR was utilized to measure the mRNA gene expression of important genes in WAT that were not available on the Quantigene Plex used. Total RNA was utilized as a template to make complementary DNA via the polymerase chain reaction (PCR) following the specified protocol for a Transcriptor First Strand cDNA synthesis kit (Roche Applied Sciences Cat. \#: 04897030001). The cDNA was amplified and quantified for gene expression levels using LightCycler $480{ }^{\circledR}$ SYBR Green I Master chemistry (Roche Applied Sciences) for qPCR determination of Nrf2, Nqo1, and Gclc. Rpl13a was used as the housekeeping gene for normalization.

\section{Statistical Analysis}

Statistical analyses of data were performed using a one-way analysis of variance and further analyzed by a Dunnett's Test post hoc test to determine significant difference between control and each treatment group. $p<0.05$ was considered statistically significant. Unless otherwise stated, all data were presented as mean \pm SE of nine animals (control) and eight animals ( 1 and $3 \mathrm{mg} / \mathrm{kg}$ doses). Statistica v.9 (StatSoft, Tulsa, OK) was used for statistical analysis.

\section{RESULTS}

\section{Effect of Developmental Exposure on Physiological Parameters and the Expression of Genes Related to Glucose Homeostasis in WAT}

The physiological data collected prior to necropsy showed no significant differences in BW between pups that were exposed to vehicle or deltamethrin during development (Figure 1A), and the blood glucose concentration was similar between both treatments compared to control (Figure 1B). The expression of a predominant insulin-responsive gene and two 
essential glucose transporters in WAT was determined using Luminex $100 \times$ MAP technology. Figure 1C shows that there were some differences between the gene expression of insulin responsive genes and glucose transport genes, Irs-1, Glut4, and Glut2, in WAT. Developmental deltamethrin $(1 \mathrm{mg} / \mathrm{kg})$ exposure decreased Glut4 (31\%), and both deltamethrin doses significantly decreased Glut2 mRNA (83\%, 82\%). No changes in Irs-1 mRNA expression were observed. These data are supported by the blood glucose measurements that were also found to be unchanged with perinatal deltamethrin exposure.

\section{Effect of Developmental Deltamethrin Exposure on Expression of Genes Related to Adipogenesis and Lipogenesis in WAT}

There were no significant differences in BW between the male pups that were exposed to vehicle or deltamethrin during development at 5 months of age (Figure 1A), but because of the significant decrease in mRNA expression in glucose transport the primary functions of adipose tissue, development of adipocytes, and lipid transport and metabolism should be described. Expression levels of lipogeneic genes in WAT and the well-described regulators of adipo-genesis were determined using Luminex 100×MAP technology. Significant decreases in the expression of lipogenic genes Srebp1 (28\%), Acc-1 (44\%), Fabp4 (19\%), $\mathrm{Cd} 36$ (21\%), Lpl (22\%), and Scd-1 (22\%) were observed in the 1-mg/kg treatment group compared to control. Furthermore, no changes in the expression of any of the lipogeneic genes measured were observed in the $3-\mathrm{mg} / \mathrm{kg}$ treatment group (Figure $2 \mathrm{~A}$ ). The relative gene expression of adipogenesis regulators ( $\operatorname{Ppar} \gamma, \operatorname{Cebp} a$, and $\operatorname{Cebp} \beta)$ is illustrated in Figure 2B. Perinatal deltamethrin exposure $(1 \mathrm{mg} / \mathrm{kg})$ decreased Ppar $\gamma$ and Cebp $a$ expression in WAT $28 \%$ and $32 \%$, respectively, compared to vehicle controls. Cebp $\beta$ expression in WAT was similar for all groups. A potential further upstream regulator of adipogenesis and lipid metabolism in adipose issue is Nrf2 [13, 21]. Nrf2 and its target genes Nqo1 and Gclc were measured by qPCR, using LightCycler $480{ }^{\circledR}$ SYBR Green chemistry and instrumentation, and presented in Figure 2C. Nrf2, Nqo1, and Gclc were all significantly downregulated at the $1 \mathrm{mg} / \mathrm{kg}$ treatment. Nrf2 was decreased to $27 \%, \mathrm{Nqo} 1$ to $13 \%$, and Gclc to $11 \%$ of the control. The decreased mRNA of the downstream target genes of Nrf2 suggests the decreased protein level or activity of Nrf2, which if a decrease could potentially explain the down-regulation of gene expression by perinatal deltamethrin exposure.

\section{Effect of Developmental Deltamethrin Exposure on Cytokine mRNA Expression in WAT}

Tnf, Ccl-2, Cd11c, Fas/Tnf-R, Cd209e, and Il4 cytokine levels in WAT were measured in 5month-old male pups that were exposed to deltamethrin via peri-natal exposure. Significant decreases in cytokine levels for both treatment groups were observed when compared to the control group (Figure 3). Tnf levels decreased $63 \%$ in the $3-\mathrm{mg} / \mathrm{kg}$ treatment group, compared to the control group. Tnf expression was similar between control pups and pups exposed to the $1 \mathrm{mg} / \mathrm{kg}$ developmental deltamethrin dose. Cd11c expression was only decreased in the $3-\mathrm{mg} / \mathrm{kg}$ group by $66 \%$ compared to control. Tnf-R expression was markedly decreased 70\% (1 mg deltamethrin $/ \mathrm{kg}$ ) and 75\% (3 mg deltamethrin $/ \mathrm{kg}$ ) when compared to the control group. Cd209e levels were decreased to $39 \%$ of control in the 1$\mathrm{mg} / \mathrm{kg}$ treatment group but were similar to controls in the $3-\mathrm{mg}$ deltamethrin $/ \mathrm{kg}$ group. 
There were no significant differences in Ccl-2 and Il4 cytokine levels compared to the control in either the 1 -or $3-\mathrm{mg} / \mathrm{kg}$ treatment group.

\section{DISCUSSION}

Deltamethrin and other pyrethroids have been established as safe pesticides based on data showing decreased toxicity in mammals from rapid metabolism to nontoxic or less-toxic forms of the parent compound [3]. Many pharmacokinetic and dynamic studies have elucidated that a portion of orally administered pyrethroids partition into fatty tissues, in which they persist for at least 3 weeks $[3,22,23]$. Deltamethrin can be detected in the adipose tissue of rats with a half-life of 5-6 days [24] and is most persistent in the body fat of animal models [3]. The retention of these highly lipophilic pesticides in metabolically active adipose tissue should increase the spectrum of research from not only neurotoxicity but to the possibility of metabolic effects of pyrethroid exposure, especially in susceptible populations. In this study, we showed that developmental deltamethrin affects adipogenesis and lipid homeostasis at the transcriptional level, decreasing the expression of some genes in the offspring of dams exposed to $1 \mathrm{mg} / \mathrm{kg}$ every 3 days. Previous toxicological studies noted non-dose-dependent reduction in BW gain in adult rats and dogs following short-term exposure $(0.1-10 \mathrm{mg} / \mathrm{kg})$ and decreased fetal weight in rabbits at $16 \mathrm{mg} / \mathrm{kg}$ perinatal exposure [15]. In a reproductive study on deltamethrin using rats, Abdel-Khalik et al. [25] observed a significant dose-dependent difference $(p<0.01)$ in mean fetal weights and retardation of fetal growth at all doses tested $(1,2.5$, and $5 \mathrm{mg} / \mathrm{kg})$. These observations of retarded development of body mass correlate to the transcriptional downregulation in gene expression for the major transcription factors of adipogenesis, Ppar $\gamma$ and Cebpa, which regulate adipocyte development and maintain adipocyte phenotype through regulation of downstream targets $\mathrm{Cd} 36, \mathrm{Lpl}$, and Glut4. A significant downregulation of cytokines excreted by WAT that are involved directly in the T-cell response (Tnf, Fas/Tnf-R, Cd209e) has a direct influence on the development of adipocytes. Decreased levels of these cytokines potentially may contribute to an altered primary immune response of dendritic cells (Cd209e), initiation of programmed cell-death by recruitment of caspase (Fas/Tnf-R), or alteration of macrophage $\operatorname{Tnf} a$ secretion, which could impact adipocyte differentiation and proliferation. The expression of fatty acid uptake genes, Fabp4, Cd36, and Lpl, regulated by Ppar $\gamma$, was downregulated, consistent with an overall metabolic change in gene expression for the pathway. The downregulation of Srebp1c, a transcription factor abundant in WAT that regulates and maintains lipid homeostasis through downstream targets Acc-1 and Scd-1, contributes further to alterations in the metabolic state of WAT in the developing mice. The reported nonmonotonic dose-response of changes in gene expression cannot be explained by previous observations or our physiological findings.

The physiological data herein describing cohorts of developmentally exposed male mice conflicts with previously reported toxicological observations for reproductive and developmental toxicity studies in rats, which reported significant changes in BW and WAT mass [15]. No significant difference in BW and liver weight was observed between vehicle and deltamethrin-treated groups in multiple cohorts of 4, 5, and 11-12 months of age male mice (data not shown). However, the finding that developmental deltamethrin exposure increases locomotor activity may confound the interpretation of potential BW changes and 
metabolic phenotypic changes (Richardson et al., personal communication), which is why the significant changes in regulators of adipogenesis and lipid metabolism at the mRNA level suggest potential underlying epigenetic effects.

Little is known regarding the effect of deltamethrin on glucose homeostasis, metabolic, or immune response. Our data suggest that developmental deltamethrin exposure had no marked effect on glucose homeostasis based on blood glucose concentrations, but significant changes in the relative gene expression of Glut 4 and Glut 2 in WAT are noted. Glut 4 is a major glucose transporter in WAT that if downregulated will decrease the insulin-responsive uptake of glucose into the cells, but the significant downregulation of Glut2 at both treatment doses, a major glucose transporter in the liver, has the potential to affect glucose transport between adipose tissue, plasma, and potentially liver. A decrease in the glucose transport genes may alter the deposition of glucose. Early insulin resistance has been linked to adipose tissue dysfunction [26], and decreased WAT expandability is associated with increased risk for diabetes or glucose intolerance [21,27,28]. Thus, deltamethrin might affect the normal response to high-fat diet challenge or treatment with thiazolidinedones, which promote adipogenesis to improve insulin resistance.

The transcriptional downregulation of genes essential for adipose development and lipid metabolism in offspring after perinatal exposure to $1 \mathrm{mg} / \mathrm{kg}$ dose of deltamethrin provides data that support the potential for metabolic effects of deltamethrin exposure during development with regard to WAT expandability. Nrf2, normally known for its role in oxidative stress, has recently been shown to be a regulator of adipose development and function [12]. Nrf2 has been shown to be an upstream regulator of Ppar $\gamma$ and Cebpa, in which Nrf2 knockout in MEF cells decreased lipid accumulation, decreased Ppar $\gamma$ and Cebp $a$ expression at the protein, along with downstream target genes [13]. Therefore, the decreased expression of Nrf2 and its target genes at the mRNA level can serve as initial evidence that Nrf2 may be involved in the gene expression changes related most specifically to the transcription factors Ppar $\gamma$ and Cebp $a$, and therefore, lead to changes in glucose and lipid homeostasis. These significant changes in gene expression at the transcriptional level may correlate to an epigenetic regulation in the offspring that may eventually lead to altered responses of WAT to environmental toxicants (i.e., obesogens, endocrine disruptors) or changes in diet (i.e., high-fat diet); however, these changes did not manifest in significant alteration in physiological parameters. To summarize, perinatal deltamethrin exposure did not result in measurable changes in BW in male offspring at 5 months of age, but did decrease the expression of some genes related to adipogenesis, lipogenesis, and inflammation in WAT that may potentially be under the regulation of alterations in Nrf2 activity.

\section{Acknowledgments}

Angela Baker was provided a graduate fellowship by Bristol-Myers Squibb. Drs. Slitt, Richardson, and Aleksunes are recipients of the NIEHS Outstanding New Investigator Scientist (ONES) Award. This study represents collaborative effort of these investigators resulting from the ONES program and is an invited submission highlighting work performed by ONES recipients.

Contract Grant Sponsor: National Institute of Health. 
Contract Grant Numbers: 4R01ES016042, 5K22ES013782, R01ES015991, T32ES007148, and P30ES005022.

Contract Grant Sponsor: National Center for Research Resources.

Contract Grant Number: 5P20RR016457.

Contract Grant Sponsor: Institute for General Medical Science.

Contract Grant Number: P20 GM103430.

\section{REFERENCES}

1. Shafer TJ, Meyer DA, Crofton KM. Developmental neurotoxicity of pyrethroid insecticides: critical review and future research needs. Environ Health Perspect. 2005; 113(2):123-136. [PubMed: 15687048]

2. Ray DE, Fry JR. A reassessment of the neurotoxicity of pyrethroid insecticides. Pharmacol Ther. 2006; 111(1):174-193. [PubMed: 16324748]

3. Soderlund DM, Clark JM, Sheets LP, Mullin LS, Piccirillo VJ, Sargent D, Stevens JT, Weiner ML. Mechanisms of pyrethroid neurotoxicity: implications for cumulative risk assessment. Toxicology. 2002; 171(1):3-59. [PubMed: 11812616]

4. Sheets LP. A consideration of age-dependent differences in susceptibility to organophosphorus and pyrethroid insecticides. Neurotoxicology. 2000; 21(1-2):57-63. [PubMed: 10794385]

5. Horton MK, Rundle A, Camann DE, Boyd Barr D, Rauh VA, Whyatt RM. Impact of prenatal exposure to piper-onyl butoxide and permethrin on 36-month neurodevelopment. Pediatrics. 2011; 127(3):e699-e706. [PubMed: 21300677]

6. Berkowitz GS, Obel J, Deych E, Lapinski R, Godbold J, Liu Z, Landrigan PJ, Wolff MS. Exposure to indoor pesticides during pregnancy in a multiethnic, urban cohort. Environ Health Perspect. 2003; 111(1):79-84. [PubMed: 12515682]

7. Morgan MK, Sheldon LS, Croghan CW, Jones PA, Chuang JC, Wilson NK. An observational study of 127 preschool children at their homes and daycare centers in Ohio: environmental pathways to cis- and transpermethrin exposure. Environ Res. 2007; 104(2):266-274. [PubMed: 17258193]

8. Naeher LP, Tulve NS, Egeghy PP, Barr DB, Adetona O, Fortmann RC, Needham LL, Bozeman E, Hilliard A, Sheldon LS. Organophosphorus and pyrethroid insecticide urinary metabolite concentrations in young children living in a southeastern United States city. Sci Total Environ. 2010; 408(5):1145-1153. [PubMed: 19896164]

9. Whyatt RM, Garfinkel R, Hoepner LA, Holmes D, Borjas M, Williams MK, Reyes A, Rauh V, Perera FP, Camann DE. Within- and between-home variability in indoor-air insecticide levels during pregnancy among an inner-city cohort from New York City. Environ Health Perspect. 2007; 115(3):383-389. [PubMed: 17431487]

10. Bouwman H, Sereda B, Meinhardt HM. Simultaneous presence of DDT and pyrethroid residues in human breast milk from a malaria endemic area in South Africa. Environ Pollut. 2006; 144(3): 902-917. [PubMed: 16564119]

11. White UA, Stephens JM. Transcriptional factors that promote formation of white adipose tissue. Mol Cell Endocrinol. 2010; 318(1-2):10-14. [PubMed: 19733624]

12. Xue PHY, Chen Y, Yang B, Fu J, Zheng H, Yarborough K, Woods CG, Liu D, Yamamoto M, Zhang Q, Andersen ME, Pi J. Adipose deficiency of Nrf2 in ob/ob mice results in severe metabolic syndrome. Diabetes. 2012 published online before print.

13. Pi JLL, Xue P, Wang W, Hou Y, Liu D, Yehuda-Shnaidman E, Lee C, Lau J, Kurtz TW, Chan JY. Deficiency in the nuclear factor e2-related factor-2 transcription factor results in impaired adipogenesis and protects against diet-induced obesity. J Biol Chem. 2010; 285(12):9292-9300. [PubMed: 20089859]

14. Trayhurn P, Beattie JH. Physiological role of adipose tissue: white adipose tissue as an endocrine and secretory organ. Proc Nutr Soc. 2001; 60(3):329-339. [PubMed: 11681807]

15. WHO. Deltamethrin environmental health criteria No. 97. World Health Organization; Geneva, Switzerland: 1990. 
16. Caudle WM, Richardson JR, Wang M, Miller GW. Peri-natal heptachlor exposure increases expression of presynaptic dopaminergic markers in mouse striatum. Neurotoxicology. 2005; 26(4): 721-728. [PubMed: 16112329]

17. Richardson JR, Caudle WM, Wang MZ, Dean ED, Pennell KD, Miller GW. Developmental heptachlor exposure increases susceptibility of dopamine neurons to N-methyl-4-phenyl-1,2,3,6tetrahydropyridine (MPTP)in a gender-specific manner. Neurotoxicology. 2008; 29(5):855-863. [PubMed: 18577399]

18. Richardson JR CW, Wang M, Dean ED, Pennell KD, Miller GW. Developmental exposure to the pesticide dieldrin alters the dopamine system and increases neurotoxicity in an animal model of Parkinson's disease. FASEB J. 2006; 20(10):1695-1697. [PubMed: 16809432]

19. Kavlock R, Chernoff N, Baron R, Linder R, Rogers E, Carver B, Dilley J, Simmon V. Toxicity studies with decamethrin, a synthetic pyrethroid insecticide. J Environ Pathol Toxicol. 1979; 2(3): 751-765. [PubMed: 370325]

20. Godin SJ DM, Hughes MF, Ross DG, Scollon EJ, Starr JM, Setzer RW, Conolly RB. Physiologically based pharmacokinetic modeling of deltamethrin: development of a rat and human diffusion-limited model. Toxicol Sci. 2010; 115(2):330-343. [PubMed: 20200215]

21. Xu J, Kulkarni SR, Donepudi AC, More VR, Slitt AL. Enhanced Nrf2 activity worsens insulin resistance, impairs lipid accumulation in adipose tissue, and increases hepatic steatosis in leptindeficient mice. Diabetes. 2012; 61(12):3208-3218. [PubMed: 22936178]

22. Kim HJ, Gonzalez-Techera A, Gonzalez-Sapienza GG, Ahn KC, Gee SJ, Hammock BD. Phageborne peptidomimetics accelerate the development of polyclonal antibody-based heterologous immunoassays for the detection of pesticide metabolites. Environ Sci Technol. 2008; 42(6):20472053. [PubMed: 18409635]

23. Kim HJ, McCoy M, Gee SJ, Gonzalez-Sapienza GG, Hammock BD. Noncompetitive phage antiimmunocomplex real-time polymerase chain reaction for sensitive detection of small molecules. Anal Chem. 2010; 83(1):246-253. [PubMed: 21141939]

24. Marei AE, Ruzo LO, Casida JE. Analysis and persistence of permethrin, cypermethrin, deltamethrin, and fenvalerate in the fat and brain of treated rats. J Agric Food Chem. 1982; 30(3): 558-562. [PubMed: 7096807]

25. Abdel-Khalik MM, Hanafy MS, Abdel-Aziz MI. Studies on the teratogenic effects of deltamethrin in rats. Dtsch Tierarztl Wochenschr. 1993; 100(4):142-143. [PubMed: 8486089]

26. Yang X, Jansson PA, Nagaev I, Jack MM, Carvalho E, Sunnerhagen KS, Cam MC, Cushman SW, Smith U. Evidence of impaired adipogenesis in insulin resistance. Biochem Biophys Res Commun. 2004; 317(4):1045-1051. [PubMed: 15094374]

27. Virtue S, Vidal-Puig A. Adipose tissue expandability, lipotoxicity and the metabolic syndromean allostatic perspective. Biochim Biophys Acta. 2010; 1801(3):338-349. [PubMed: 20056169]

28. Slawik M, Vidal-Puig AJ. Adipose tissue expandability and the metabolic syndrome. Genes Nutr. 2007; 2(1):41-45. [PubMed: 18850138] 
(A)

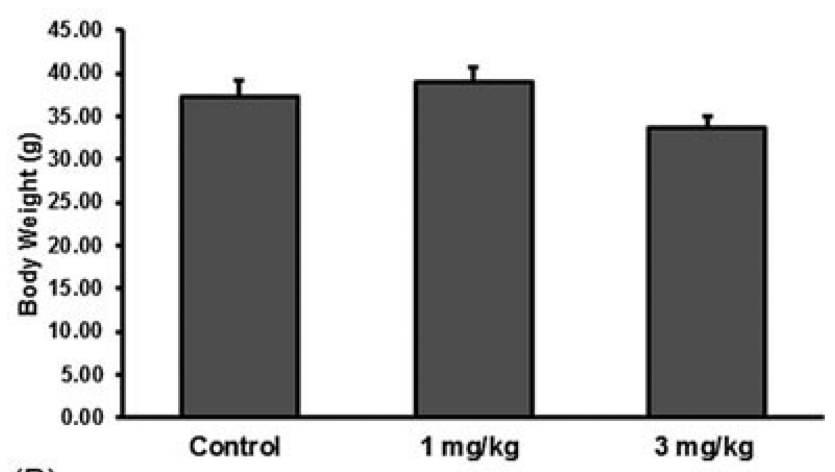

(B)

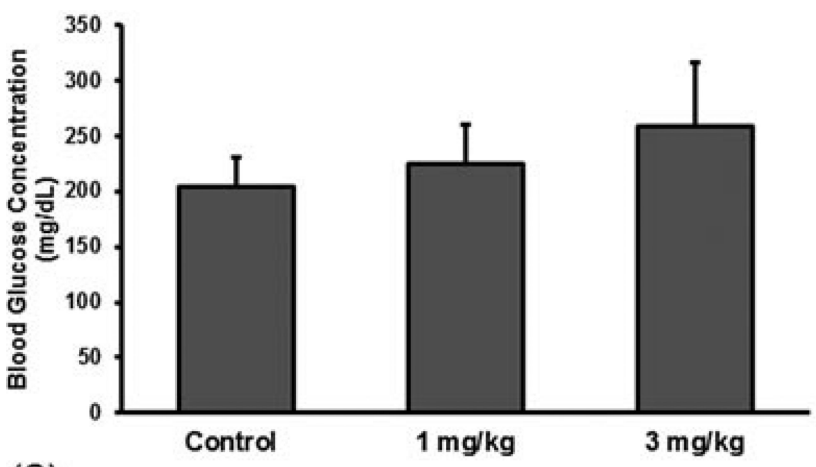

(C)

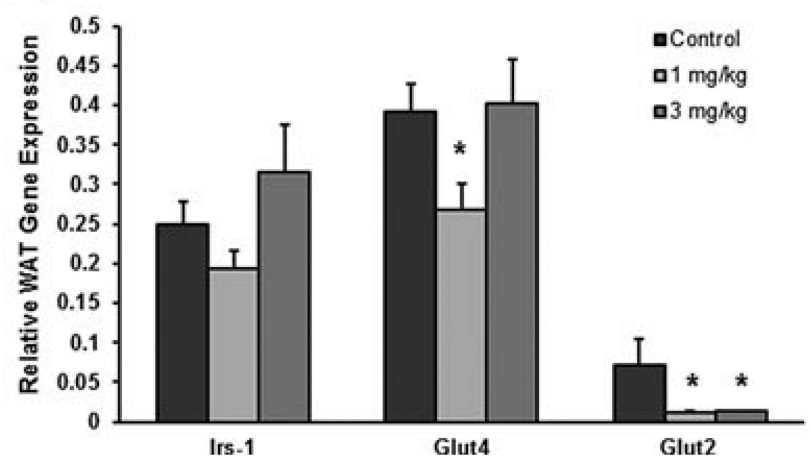

FIGURE 1.

Body weight was used to describe any potential metabolic effects of perinatal deltamethrin exposure, along with blood glucose concentration and mRNA gene expression of key factors in insulin response of WAT to describe potential effects on glucose homeostasis. Body weights of 5-month-old male mice were taken prior to sacrifice. (A) Average body weight $(g)$ of each treatment group expressed as a mean BW \pm SEM $(n=6-7)$. (B) Blood glucose level taken at time of necropsy of 5-month-old adult male mice expressed as a mean BG \pm SEM $(n=5-6-)$. mRNA gene expression data in WAT of 5-month-old adult male mouse pups from dams exposed to 0,1 , or $3 \mathrm{mg}$ deltamethrin/kg every 3 days during getation and lactation. Total RNA was isolated from WAT, and mRNA levels were Quantified by Quantigene Plex 2.0 assay. All gene expression data were normalized to Rpl13a (no significant change in gene expression) and are expressed as mean \pm SEM $(n=8-9)$. (C) Insulin responsive and glucose transport: Irs-1, Glut-4, Glut- 2 mRNA expression. mRNA 
gene expression data in WAT of 5-month-old adult male mouse pups from dams exposed to 0,1 , or $3 \mathrm{mg}$ deltamethrin $/ \mathrm{kg}$ every 3 days during gestation and lactation. * and \# represent statistical difference between control and treatment doses $(p<0.05$ and $p<0.005$, respectively). 
(A)

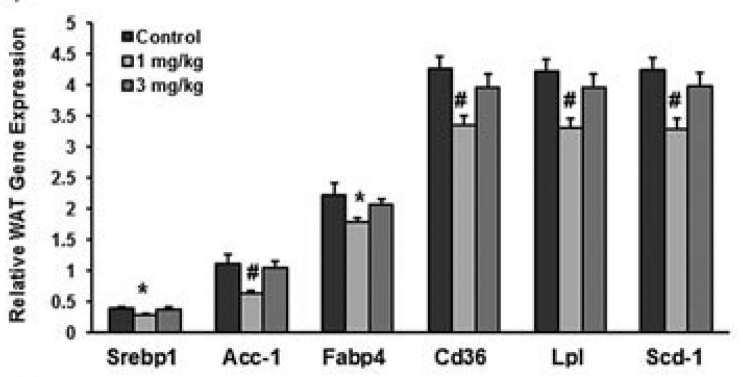

(B)

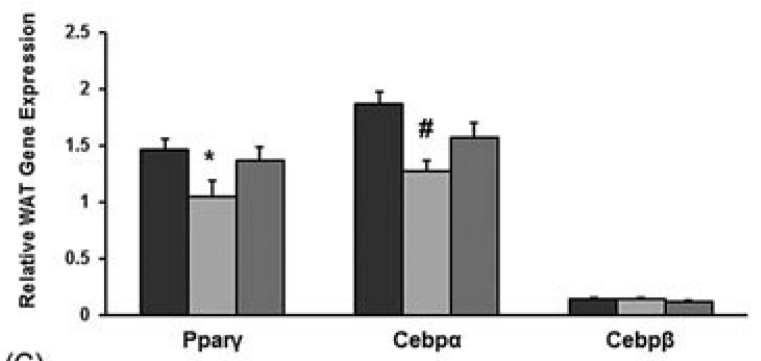

(C)
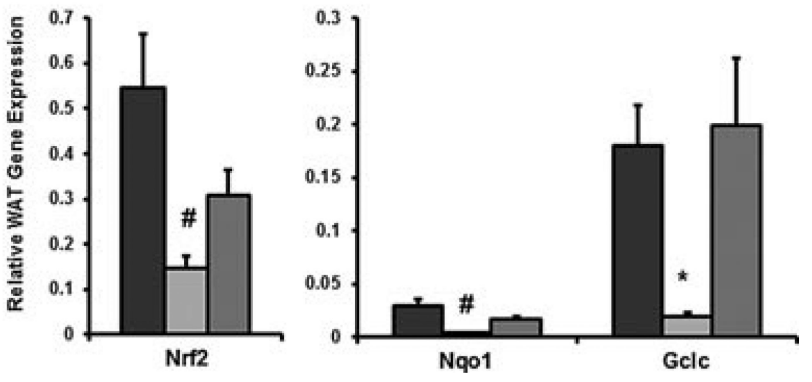

FIGURE 2.

mRNA gene expression data in WAT of 5-month-old adult male mouse pups from dams exposed to 0,1 , or $3 \mathrm{mg}$ deltamethrin/kg every 3 days during gestation and lactation. Total RNA was isolated from WAT, and mRNA levels were quantified by Quantigene Plex 2.0 assay. All gene expression data were normalized to Rpl13a (no significant change in gene expression) and are expressed as mean \pm SEM ( $n=8-9)$. (A) Lipogenic genes: Srebp1, Acc-1, Fabp4, Cd36, Lpl, Scd-1 mRNA expression. (B) Regulators of adipogenesis: Ppar $\gamma$, Cebp $a, \operatorname{Cebp} \beta$ mRNA expression. (C) mRNA gene expression for Nrf2, Nqo1, and Gclc was quantified by a Light-cycler 480 SYBR green qPCR method. Nrf2, Nqo1, and Gclc mRNA expression * and \# represent statistical difference between control and treatment doses $(p<0.05$ and $p<0.005$, respectively). 


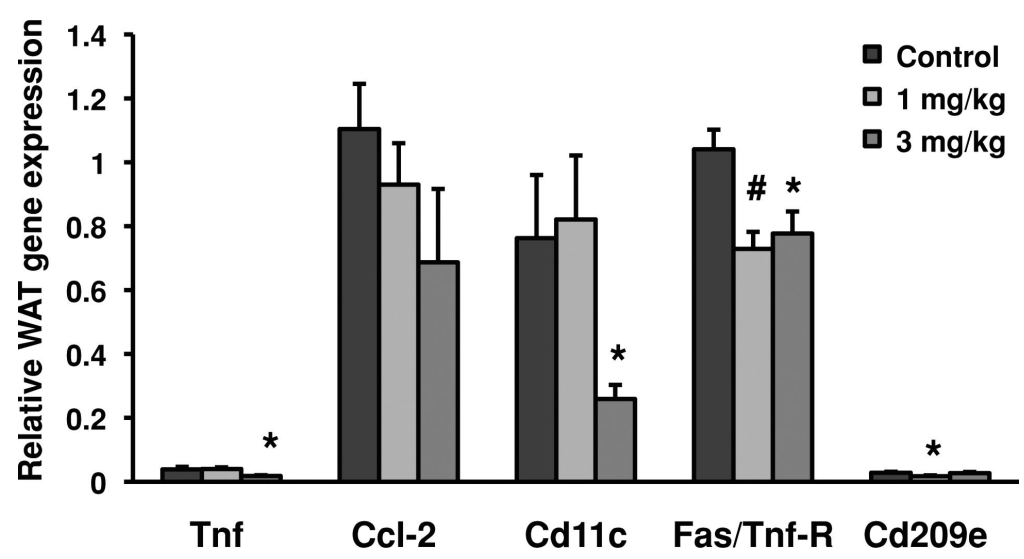

FIGURE 3.

mRNA gene expression of cytokines in WAT of 5-month-old adult male pups from dams exposed to 0,1 , or $3 \mathrm{mg}$ deltamethrin/ $\mathrm{kg}$ every 3 days during gestation and lactation. Total RNA was isolated from WAT, and mRNA levels were quantified by Quantigene Plex 2.0 assay. All gene expression data were normalized to Rpl13a (no significant change in gene expression) and are expressed as mean \pm SEM $(n=8-9)$ Cytokines: Tnf, Ccl-2, Cd11c, Fas/ Tnf-R (M1 macrophage markers) and Cd209e (M2 macrophage marker). * and \# represent statistical difference between control and treatment doses $(p<0.05$ and $p<0.005$, respectively). 